\title{
THE DISSEMINATION OF THE GENEVA CONVENTIONS
}

The official review of the German Red Cross in the German Federal Republic Deutsches Rotes Kreuz published an article in its issue of July 1965, in which mention was made, inter alia, of a new brochure concerning the dissemination of the Geneva Conventions, which has recently been produced by that National Society, "Landesverband ", Westphalia-Lippe, Münster. It should also be pointed out that this publication of some 45 pages is an annex to the primer published in 1963 entitled Im Geiste von Solferino (In the spirit of Solferino) which was mentioned in the February 1965 number of the International Review. We now give a few details of this second publication.

Entitled Die Genfer Rotkreuz-Abkommen (Begleitheft für den Unterricht mit der Fibel ("Im Geiste von Solferino"), it is intended, as indicated by its title, to supply all necessary explanations relating to the series of illustrations contained in the primer and depicting the essential principles of the Geneva Conventions in a most symbolic and graphic manner. In view of the very favourable reception which this work was given from the outset, both by the young and also by teachers, its authors therefore decided to pursue their efforts in this sphere and worked over the past two years in preparing this second brochure. Also illustrated, it begins with an interesting description of the Geneva Conventions of 1864, 1906, 1929 and 1949, briefly recalling the rôle played by the Red Cross in drawing up these Conventions, in particular that of August 22, 1864, which bears on the amelioration of the condition of the wounded in armies in the field. It should be pointed out that these commentaries have been written by Mr. A. Schlögel, SecretaryGeneral of the National Society. After this explanatory opening, the work continues with a series of articles and texts especially written for the young but which will appeal equally to the general public.

It goes without saying that this interesting initiative will be of great service to the Red Cross cause in that country and that such instruction will considerably contribute, in the name of Red Cross principles, to ensure its effectiveness.

The National Red Cross, one can see, devotes all its efforts to publicising as widely as possible, and especially amongst the 


\section{IN THE RED CROSS WORLD}

young, a knowledge of the Geneva Conventions to which it attaches such importance. We therefore wish for this initiative all the success it deserves, hoping that it may inspire other National Societies to follow suit.

\section{Afghanistan}

The Afghan Red Crescent Society has communicated information to the ICRC on the widespread and successful relief action carried out a few months ago. We quote details below, for they give an idea of the extent of the disaster which ravaged part of the country and of the effectiveness of the immediate help rendered by the Society.

During the month of May, due to unusually heavy Spring rains, the Helmand River and its tributaries rose to flood level. Vast areas of the Chackansoor Province, in southwestern Afghanistan, were flooded, causing thousands of people to be left homeless. Many families had to be evacuated from the area.

The Afghan Red Crescent Society dispatched a rescue and relief team, headed by Prof. Mohammed Ousman Anway, M.D., the Secretary General of the A.R.C.S., to the area on May 10th. The work of this team was carried out in motor boats, airplanes and helicopters.

Since the roads were all flooded, an inspection of this area had to be carried out by helicopter. The A.R.C.S. team was accompanied during this inspection by the Acting Governor of the Chackansoor Province and the Military Commandant of Kandahar. During this inspection, the team fixed certain sites as centres for the distribution of relief supplies of wheat, sugar, tea, clothing and medicaments and they organized the transportation of these supplies by motor boat and helicopter.

After the inspection, the supplies were transported-a very difficult operation through thick swamp areas-from Musa Qala to Kang. Several members of the team suffered from sun stroke during this hazardous operation but the supplies finally arrived at the distribution centers after 21 hours. 